\title{
EDITORIAL
}

\author{
Derk Loorbach \\ Dutch Research Institute for Transitions, Erasmus University Rotterdam
}

\section{Governance for sustainability}

Sustainable development is rapidly moving from the periphery to the mainstream of politics, business, and science. Over the past several years, a strong consensus has started to emerge that some major global problems can only be overcome through largescale concerted action. Recent additions to the debate include the reports by the International Panel on Climate Change, the Stern Report on the economics of climate change, Al Gore's "An Inconvenient Truth," and, perhaps less known, the Potsdam Memorandum. The latter pronouncement, recently presented by a broad group of Nobel laureates and entitled "The Great Transformation" pleads for fundamental changes in our economies and societies, asking,

Is there a "third way" between environmental destabilization and persisting underdevelopment? Yes, there is, but this way has to bring about, rapidly and ubiquitously, a thorough re-invention of our industrial metabolism - the Great Transformation. This is an awesome challenge, yet we have one comparative advantage over all previous generations: an incredibly advanced system of knowledge production that can be harnessed, in principle, to co-generate that transformation together with courageous political leaders, enlightened business executives and civil society at large (Potsdam Institute for Climate Impact Research, 2007).

Since 2001, an experiment has been ongoing in the Netherlands to answer this call for a novel governance paradigm dealing with long-term social change. The emerging theoretical and practical results of "transition management" offer interesting insights for transforming science and policy for sustainable development. Transition management is being codeveloped in theory and practice by a wide network of scholars, policy makers, businesses, and nongovernmental organizations (NGOs). Since its introduction in the Fourth National Environmental Policy Plan (NEPP) six years ago, this experimental governance approach has been implemented in the areas of sustainable energy supply, mobility, agriculture, health care, and water management (VROM, 2001). Transition management is a coordinated effort to influence the speed and direction of large-scale social change based on the concepts of social transitions and sustainable development (Rotmans et al. 2001; Loorbach, 2007). Due to its extensive experience with environmental planning and coordinated innovation policy, the research and policy communities in the Netherlands have developed capacity for close cooperation and produced successful environmental policies. However, in spite of Dutch achievements over the past few decades, several problems persist for which existing policy or market instruments have proved ultimately inadequate. Neither top-down government policies nor bottom-up market forces can alone support directed long-term sectorwide changes; they can only occur through combinations of government policies, market forces, and bottom-up initiatives from civil society.

The unsustainability of contemporary society lies in persistent problems that are deeply rooted within our social structures, involve multitudes of actors, evolve on various scales, and require a very longterm perspective to understand and, presumably, to manage effectively (Rotmans, 2005). Society is regularly confronted with the symptoms of these persistent problems, such as energy crises, air and water pollution, environmental degradation, congestion, and ill health. Various sciences traditionally try to understand or address these problems through disciplinary analyses and the formulation of specialized solutions, but it appears that with each iteration the extant dilemmas become more complex and harder to manage.

Let us consider the mobility issue wherein measures to increase road capacity or to decrease emissions target traffic jams and automotive air pollution. Although such approaches generate incremental short-term improvements, they foster predictable mobility increases that ultimately intensify both congestion and pollution. From this perspective, sustainable development implies breaking with traditional 
routines and modes of thinking to overcome the inertia that limits innovation. In other words, new expressions of the same policy approaches-whether grounded in government regulations or market incentives - are unable to correct the range of problems that earlier interventions have created.

To deal effectively with persistent social problems, transitions-long-term continuous processes that fundamentally change a social subsystem - are necessary. Such transitions are recurring patterns of sociotechnical change in culture, structure, and practices. History has witnessed numerous transitions in economy, agriculture, mobility, and energy, but also in areas such as education, health care, and social structure (Rotmans et al. 2001; Geels, 2004). In these domains, relatively long temporal stretches of stability have alternated with relatively short periods of rapid social change. Transition management is based on an evolving understanding of these patterns and mechanisms. Various scientific disciplines have contributions to make here including ecology, biology, complexity science, and physics as well as the more socially and technologically oriented disciplines such as sociology, psychology, demography, science and technology studies, and history. Internationally, transition management is also recognized as an inspiring integrative concept, as it is slowly entering the debate in complexity science, governance, ecosystems management, and innovation research. Although different disciplines describe transition processes using their own terminologies, discourses, methodologies, and scales, a number of striking commonalities exist. Common points of agreement are:

- Transitions are the result of alternating processes of slow and rapid change leading from one relatively stable state to another.

- Transitions are the result of coevolutionary processes occurring at different levels of scale.

- Transitions are highly unpredictable and uncertain in terms of their speed and direction.

- Transitions are driven by changes in the external environment of a system as well as internal innovation.

The ambition of transition management is to generate processes that foster continuous social improvement while balancing economic vitality with resource use, social welfare, and cultural and social diversity. Such management of transitions can by definition not be a top-down, imperious approach. Due to inevitable complexity and uncertainty, the most influence we can expect over transitions is to shape their speed and direction. By articulating and debating desired future social states and development paths, transition management emphasizes the un- avoidable need for normative processes and governance strategies. Sustainable development should not be seen as a blueprint or a fixed goal, but rather as a guiding notion that enables both science and society to search for long-term collective goals and ambitions, to experiment in the short term, and to regularly assess progress.

Several principles, grounded in transition thinking, provide the theoretical basis for transition management. The starting point is that society is analyzed in terms of complex systems with typical behavior and mechanisms (for example coevolution, emergence, and adaptation). The basic tenets are the need to:

- Simultaneously consider different domains (multidomain), different levels of scale (multilevel), and different system states (multiphase).

- Adopt a long-term perspective (generally 25 years or more) as a framework for short-term actions.

- Employ a multi-actor approach.

- Utilize both backcasting and forecasting to reconcile uncertainties and to plan for surprises.

- Focus on social learning through learning-bydoing and doing-by-learning.

- Encourage transitions through the creation of (sociotechnical) niches.

Transition management is concerned with the functioning of the variation, selection, and reproduction process at the societal level: creating variety informed by visions of and experiments for sustainability, as well as shaping new pathways and gradually adapting existing institutional frameworks and regimes (Kemp \& Loorbach, 2006). In this sense, it is an example of what is called "reflexive governance" (Voss et al. 2006). During the past several years, experiments with this approach in both the Netherlands and Belgium have been ongoing in areas such as energy supply, housing, waste and water management, and regional development (SenterNovem, 2005). These initiatives have led to the development of a governance framework to structure implementation of the approach to and the formulation of a number of "systemic instruments." The framework distinguishes between different types of governance activities: strategic (informal processes of problem structuring and envisioning), tactical (networking, coalition building, negotiating, and developing new regulations, institutions, and structures), operational (experimenting, developing new businesses, involving consumers and citizens), and evaluation-oriented (monitoring and adjusting ambitions and agendas). 
These different activities occur simultaneously through transition processes and influence one other, but each has its own dynamic, type of actors, and impact in different phases (Loorbach, 2007).

The systemic instruments based on this framework seek to influence ongoing transitions by bringing together innovators in policy, business, science, and NGOs to redefine and reframe urgent social problems and their potential solutions. An example of such a strategic transition management instrument is the "transition arena" that encourages a group of innovative frontrunners from different organizational backgrounds to formulate an alternative vision of the future and to develop strategies outside of the existing (policy) regime on how to reach such a future. The transition approach produces a common language and mode of communication to aid strategy development and to move toward concrete action. This facilitates the creation of a community with shared goals and ambitions at a collective, system level, while allowing for disagreement and competition on a more concrete and everyday level.

The concepts of transition and transition management are an inspiring basis for debate and action among scholars and different scientific disciplines. They also offer a fruitful context for cooperation and debate among scientists, policy makers, and business managers. As an analytical concept, transition management stimulates interdisciplinary analysis and offers a framework within which to discuss similarities, contradictions, and the relative value of various disciplines in contributing to different problems. In the Netherlands, a broad transition-research network exists and includes economists, historians, political scientists, technology and innovation experts, and consumption researchers with each specialist group focusing on particular aspects of transitions at different levels (see KSI Research Network, 2005). The possibilities for transition management to contribute to substantial methodological advances appear to parallel its opportunities to enrich social and policy practices. As a governance approach, transition and transition management facilitate cooperation and coproduction between science and policy, as well as the development and use of new scientific methods. New coalitions, strategies, and experiments involving pioneering scientists, "courageous political leaders, enlightened business executives and civil society at large" have been launched in the wake of transition management (Potsdam Institute for Climate Impact Research, 2007). This, in essence, is the definition of transition management as governance for sustainability: a collective process of learning-by-doing and doing-by-learning based on a shared way of thinking. The approach is not to achieve fixed goals, but to gradually work towards common ambitions through innovation, integration, and transition. And the beauty is that everyone can contribute in his or her own way and in doing so the search itself becomes the process of governance for sustainable development.

\section{References}

Geels, F. 2004. Sectoral systems of innovation to sociotechnical systems: Insights about dynamics and change from sociology and institutional theory. Research Policy 33(6-7):897-920.

Kemp, R. \& Loorbach, D. 2006. Transition management: a reflexive governance approach. In J. Voss, R. Kemp, \& D. Bauknecht (Eds.), Reflexive Governance for Sustainable Development. pp. 103-130. Northhampton, MA: Edward Elgar.

KSI Research Network. 2005. Business Plan KSI 2005. http://www.ksinetwork.nl/downs/ksi_businessplan.pdf. November 11, 2007.

Loorbach, D. 2007. Transition Management: New Mode of Governance for Sustainable Development. Utrecht: International Books.

Netherlands Ministry of Housing, Spatial Planning, and the Environment (VROM). 2001. Where There's a Will There's a World: Working on Sustainability (Fourth National Environmental Policy Plan). The Hague: VROM.

Potsdam Institute for Climate Impact Research. 2007. Potsdam Memorandum. http://www.nobel-cause.de/Pots dam_Memorandum.pdf. November 5, 2007.

Rotmans, J. 2005. Societal Innovation: Between Dream and Reality Lies Complexity. Inaugural Addresses Research in Management Series No. EIA-2005-026ORG. Rotterdam: Erasmus Research Institute of Management, Erasmus University Rotterdam. http://hdl. handle.net/1765/7293.

Rotmans, J., Kemp, R., \& Van Asselt, M. 2001. More evolution than revolution: Transition management in public policy. Foresight 3(1):15-31.

SenterNovem. 2005. Energy Transition. http://www.senter novem.nl/EnergyTransition/Index.asp. November 26, 2007.

Voss, J., D. Bauknecht, \& R. Kemp (Eds.). 2006. Reflexive Governance for Sustainable Development. Northhampton, MA: Edward Elgar.

\begin{abstract}
About the Author
Derk Loorbach is a senior researcher and consultant at the Dutch Research Institute for Transitions (DRIFT) at Erasmus University Rotterdam where he received his $\mathrm{PhD}$ in June 2007. DRIFT is an interdisciplinary institute that combines research with close cooperation with policy and business to further sustainable development in practice. A central theme in Loorbach's research is the development of the transition-management approach as a new governance model based on complex systems thinking, governance theories, and sociology. This work
\end{abstract}


is aimed at facilitating and guiding processes of social change in the direction of sustainability through transition arenas and experiments. Loorbach is currently involved in various transition arenas, innovation programs, and visioning practices as a researcher, consultant, and participant. His research is an example of "sustainability science" combining fundamental and action research to contribute to sustainable development in practice. He can be contacted at the Dutch Research Institute for Transitions, Erasmus University Rotterdam, Room M5-30, PO Box 616, 3000 DR Rotterdam, The Netherlands (email: loorbach@fsw.eur.nl). 